\section{Epidemiology and Infection}

cambridge.org/hyg

\section{Original Paper}

Cite this article: Medić S, Petrović V, Milosević V, Lozanov-Crvenković Z, Brkić S, Andrews N, de Ory F, Anastassopoulou C (2018). Seroepidemiology of varicella zoster virus infection in Vojvodina, Serbia. Epidemiology and Infection 146, 1593-1601. https://doi.org/ $10.1017 /$ S0950268818001619

Received: 17 October 2017

Revised: 1 April 2018

Accepted: 18 May 2018

First published online: 18 June 2018

Key words:

Antibodies to varicella zoster virus (anti-VZV); chickenpox; ESEN2; Europe; seroprevalence; standardisation; vaccines and immunisation

Author for correspondence:

S. Medić, E-mail: snezana.medic@izjzv.org.rs

\title{
Seroepidemiology of varicella zoster virus infection in Vojvodina, Serbia
}

\author{
S. Medić1,2, V. Petrović1,2, V. Milosević ${ }^{1,2}$, Z. Lozanov-Crvenković ${ }^{3}$, S. Brkić2, \\ N. Andrews ${ }^{5}$, F. de Ory ${ }^{6}$ and C. Anastassopoulou ${ }^{7}$
}

${ }^{1}$ Center for Disease Control and Prevention, Institute of Public Health of Vojvodina, Novi Sad, Serbia; ${ }^{2}$ Faculty of Medicine, University of Novi Sad, Novi Sad, Serbia; ${ }^{3}$ Department of Mathematics and Informatics, Faculty of Sciences, University of Novi Sad, Novi Sad, Serbia; ${ }^{4}$ Clinic for Infectious Diseases, Clinical Center of Vojvodina, Novi Sad, Serbia; ${ }^{5}$ Statistics, Modelling, and Economics Department, National Infections Service, Public Health England, London, UK; ${ }^{6}$ Laboratorio de Serología, Centro Nacional de Microbiología, Instituto de Salud Carlos III,

Majadahonda, Madrid, Spain and ${ }^{7}$ Division of Genetics, Cell and Developmental Biology, Department of Biology, University of Patras, Patras, Greece

\begin{abstract}
The present cross-sectional serosurvey constitutes the first effort to describe the varicella zoster virus (VZV) seroepidemiology in Serbia. An age-stratified serum bank of 3570 residual samples collected between 2015 and 2016 in each of the seven districts of the Vojvodina Province was tested for IgG anti-VZV antibodies with an enzyme immunoassay. Results were standardised into common units according to the European Sero-Epidemiology Network (ESEN2) methodology. Univariable and multivariable analyses were used to examine the relationships between standardised anti-VZV positivity or logarithmically transformed antibody titres and demographic features of study subjects. Seropositivity ( $85 \%$ overall) increased with age, in parallel with geometric mean titres. By the time of school entry, $68 \%$ of children were immune. The slower subsequent acquisition of immunity leaves epidemiologically relevant proportions of adolescents (7\%), young adults (6\%) and especially females of reproductive age $(6 \%)$ prone to more severe forms of varicella. In the ongoing pre-vaccine era, natural infection provides a high level of collective immunity, with the highest VZV transmission in children of preschool age. The detected gaps in VZV immunity of the Serbian population support the adoption of the official recommendations for varicella immunisation of non-immune adolescents and young adults, including non-pregnant women of childbearing age.
\end{abstract}

\section{Introduction}

Primary infection with varicella zoster virus (VZV) manifests as chickenpox, a contagious, usually benign rash illness of childhood. Reactivation of latent virus in the sensory ganglia, typically in older age, causes herpes zoster (HZ, shingles) [1]. In temperate climates, nearly every person will become infected by mid-adulthood [2]. An estimated $2-6 \%$ of varicella patients attending a general practice develop complications, while long-term sequelae have been reported in $0.4-10.1 \%$ of hospitalised patients [3]. Although the risk of complications, hospitalisations and deaths due to varicella is higher in adults, pregnant women, immunocompromised individuals and newborns, most of the disease burden occurs in healthy children [4].

The live attenuated varicella vaccine (Oka VZV strain) developed by Takahashi in 1974 is available worldwide as a monovalent or combined vaccine [5]. The World Health Organization (WHO) recommends routine childhood immunisation against varicella in countries where the disease is a relatively important public health and socio-economic problem, if the vaccine is affordable and high $(\geqslant 80 \%)$ and sustained coverage can be achieved [2]. High coverage with two doses of varicella vaccine as part of the childhood universal immunisation in some developed countries significantly reduced varicella morbidity, ambulatory visits and hospitalisation rates [3]. However, most countries in the European Union (EU)/European Economic Area (EEA) implemented targeted varicella immunisation for high-risk groups $[5,6]$.

Age-stratified serosurveys provide insights into the relative proportions of susceptible and immune individuals, as well as estimates of the age at which VZV infection is acquired [5]. The European Sero-Epidemiology Network (ESEN2) project introduced standardised VZV serological surveillance to allow for international comparisons of national results obtained with different assays; wide variations were detected in the country-specific VZV seroprofiles in Europe $[7,8]$.

Located in Southeastern Europe, the Republic of Serbia is among the countries where a routine childhood varicella immunisation has not been implemented yet. Varicella was 
designated as a notifiable disease in Serbia in 1975. Case-based notification data were available until 2005, while reporting of aggregated data was required by law thereafter. High incidence rates (470.8-684.7 cases per 100000 population) were recorded between 2006 and 2015, when varicella accounted for 10-22\% of all notifiable morbidity from infectious diseases apart from influenza [9].

Significant changes in public health legislation are currently underway in Serbia. The implementation of a recently passed law, dictating the mandatory immunisation against varicella in high-risk groups, health care workers and the recommended immunisation for persons of a certain age [10], has just begun following the adoption of a new immunisation rulebook specifying the indications for vaccination [11]. The specification of this law to lift the notifiable disease designation off varicella has already gone into effect.

Herein, we describe the current seroepidemiology of VZV infection in Vojvodina, an Autonomous Province in the north of Serbia with a population of 1931809 inhabitants, representing more than one-quarter $(26.9 \%)$ of the total population according to the most recent census [12]. To our knowledge, this is the first large VZV serosurvey to be conducted in Serbia with the main objective to obtain age-specific seroprevalence estimates. The findings of this study could help identify the gaps in the population immunity with potential implications for future vaccination strategies.

\section{Methods}

\section{Sera collection}

Serum samples from 3570 subjects (1788 males/1782 females, age range: 29 days -83 years; mean age \pm S.D.: $22.9 \pm 19.1$ years) were collected between April 2015 and March 2016 as residual diagnostic sera. Written informed consent of study participants, or their parents or legal guardians if they were $<15$ years, was obtained. Each subject provided a blood sample after a health history interview. The anonymised samples were marked only with the date of sampling and the subjects' age, gender and area of residence. Specimens of immunocompromised patients and recipients of blood and blood products during the past 6 months were excluded. All procedures contributing to this work comply with the ethical standards of the relevant national and institutional committees on human experimentation and with the Helsinki Declaration of 1975, as revised in 2008.

The serum bank was geographically representative since specimens were collected in health institutions in each of the seven districts of Vojvodina (Fig. 1). The multi-tiered age structure of the serum bank was designed as per the ESEN2 specifications [7]: $\sim 100$ samples were thus collected for each age group in the range $0-19$ years and 200 samples for each of the age groups $\geqslant 20$ years $(20-24,25-29,30-34,35-39,40-49,50-59$ and $\geqslant 60$ ), with about equal numbers of samples by gender in each age group. Samples from females of reproductive age (defined as 15-39 years old for comparison purposes to [7]) corresponded to $19.2 \%(686 / 3570)$ of all tested samples or to $38.5 \%(686 / 1782)$ of samples collected from women. For the purposes of this survey, the province was divided into three geographic areas: Northern, Central and Southern Vojvodina. The sample size of each area was proportional in accordance to the census [12]; the analogous age distribution of the population of the province and the whole country is shown in Supplementary Table S1 (on the Cambridge Journals Online website).

\section{Assay standardisation}

The ESEN2 VZV standardisation panel that had been prepared by the Spanish reference centre (Instituto de Salud Carlos III, Madrid, Spain) was tested at the Institute of Public Health (IPH) of Vojvodina with the enzyme immunoassay routinely used (anti-VZV ELISA (IgG), EUROIMMUN AG, Germany) twice: first at the beginning of the study (December 2015) and second mid-way through the testing of the serum bank (February 2016). The panel consisted of 148 samples, including 60 negative (geometric mean of antibody activity, GMAA: $<50 \mathrm{mIU} / \mathrm{ml}$ ), four low positive or equivocal (GMAA: 50$100 \mathrm{mIU} / \mathrm{ml}$ ) and 84 positive (GMAA: $>100 \mathrm{mIU} / \mathrm{ml}$ ) sera [8]. The results of the panel were plotted against those of the reference centre to obtain a standardisation equation, which would allow for the conversion of the local results of the testing of the serum bank to standard (reference laboratory) titres, as described by Kafatos et al. [13]. Sufficient variability had to be accounted for by the standardisation equation if it were to be applied to convert the serum bank results to a common unitage so that international comparisons could be made. The process of standardisation that was performed by Public Health England, London, UK, was evaluated quantitatively by determining the fit of the equation using $R^{2}$ (the square of the multiple correlation coefficient), especially in the equivocal range, and qualitatively by assessing the level of concordance in identifying positive, negative and equivocal results [13].

\section{Main serum bank testing}

Sera were stored at $-20^{\circ} \mathrm{C}$ until testing with the same commercial enzyme-linked immunoassay at the Virology laboratory of IPH of Vojvodina. The assay was performed and interpreted according to the manufacturer's instructions. The reported sensitivity of the utilised EUROIMMUN ELISA is $100 \%$ at a specificity of $95 \%$ with respect to the Wampole ELISA. Quantification of antibody titres was based on the WHO International Standard for varicella zoster immunoglobulin, the W1044 serum (Anti-Varicella Zoster Serum, $50 \mathrm{IU} / \mathrm{ml}$, Central Laboratory of the Netherlands Red Cross Blood Transfusion Service, Amsterdam, The Netherlands). The derived standardisation equation was used to convert the local semi-quantitative results of the serosurvey into standardised units by applying the reference laboratory cut-offs; results were thereby reclassified qualitatively as negative, positive or equivocal in standardised ESEN2 units. As in the original VZV standardisation during ESEN2 [7, 8], equivocal test results from samples containing low levels of anti-VZV IgG were included as seropositives in all further analyses.

\section{Statistical analysis}

Relationships between standardised anti-VZV seroprevalence or logarithmically transformed antibody titres and demographic features of study subjects (age, gender and area of residence) were examined by the $\chi^{2}$ test, $t$ test or Wilcoxon rank-sum test, as appropriate. Multivariable logistic regression was used to determine whether anti-VZV status was independently associated with a particular variable. Data were analysed using the Statistica 13 software package [14]. 


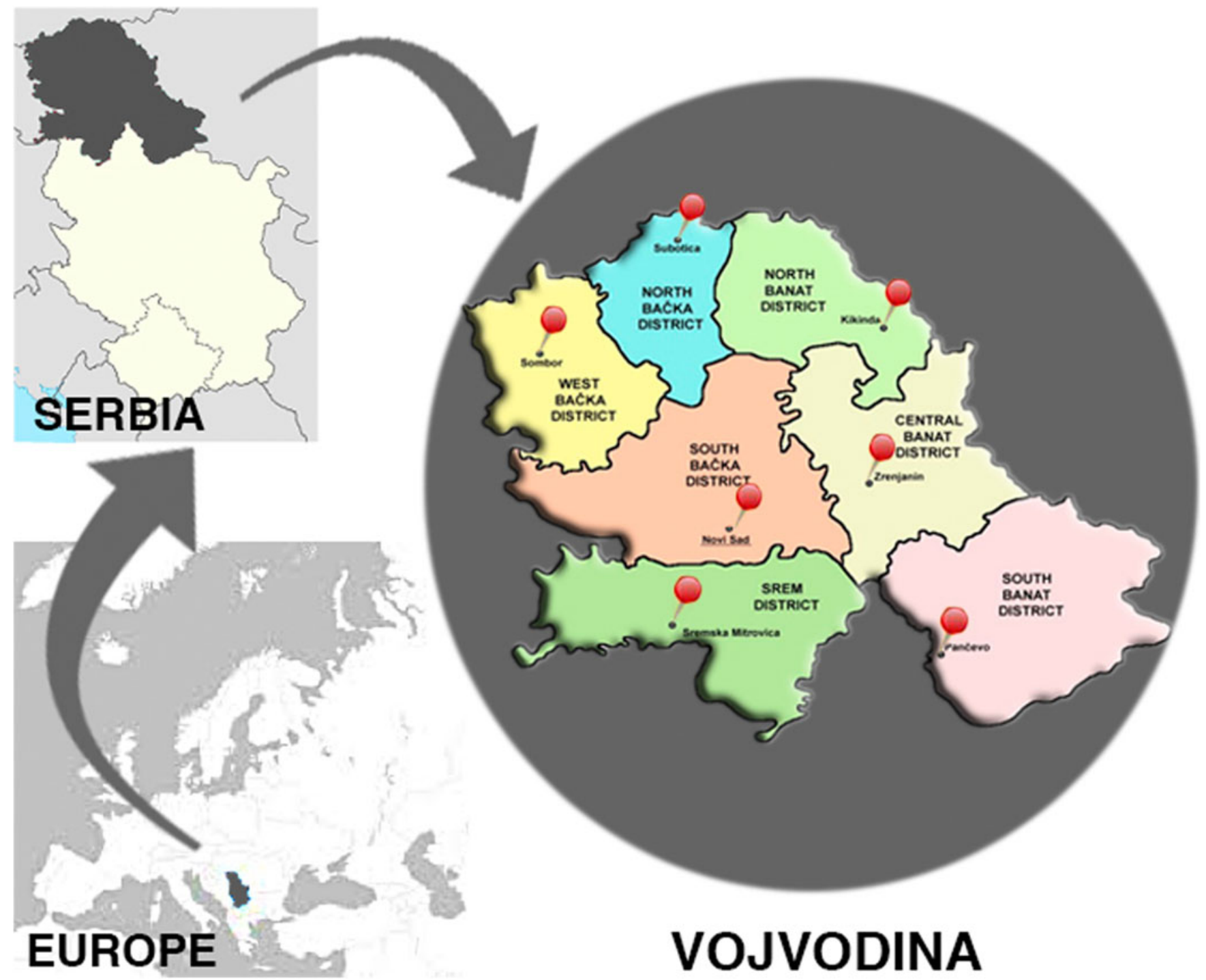

Fig. 1. Sera collection locations at health care institutions in each of the seven districts of the Autonomous Province of Vojvodina, Serbia, 2015-16. The province was divided into three main areas for the purposes of this survey: (a) Northern Vojvodina that included the districts of West Bačka, North Bačka and North Banat; (b) Central Vojvodina that included South Bačka and Central Banat and (c) Southern Vojvodina that included Srem county and South Banat.

\section{Results}

\section{Assay standardisation outcome}

The geometric mean of the two runs of the reference panel was used in the standardisation. The outcome of panel testing and the regression line that was used in the standardisation are depicted in Figure 2. Standardisation was successful as indicated by the very high obtained $R^{2}$ value $(0.94)$ and the exclusion of just one sample of the VZV reference panel as a potential outlier.

Main serum bank test results were standardised to ESEN2 units by inverting the regression line and anti-logging, using the equation:

$$
S=10^{\left(-10+\sqrt{81.63+33.33 \log _{10} U}\right)}
$$

where ' $S$ ' and ' $U$ ' are the standardised and unstandardised results, respectively. Standardisation marginally increased the proportion of positive results (from $81.8 \%$ to $83.0 \%$ ) and decreased negative ones (from $16.7 \%$ to $15.4 \%$ ). The number of equivocal results also slightly increased (from 52 to 57 ) post-standardisation; these 57 low positive samples (1.6\% of the serum bank) were re-classified as seropositives after standardisation and they were included as such in all further analyses.

\section{VZV seroprevalence and associations with demographic features}

Overall, 3021 of $3570(84.6 \%, 95 \%$ CI 83.4-85.8) sera tested positive, while $549(15.4,95 \%$ CI 14.2-16.6) tested negative for varicella IgG antibodies. No significant associations were found between VZV seropositivity and gender or area of residence (Table 1). The percentage of seropositive results increased with increasing age (except for $<1$ and 1-2 years, Table 1, Fig. 3), ranging from $41.2 \%$ ( $1-4$ years) to $99.6 \%$ (adults $\geqslant 60$ years). Multivariable logistic regression including age, gender and area of residence confirmed that the age of study subjects was the only demographic variable that was independently associated 
Fig. 2. Anti-VZV ELISA results of the standardisation panel obtained by Serbia ( $y$-axis) plotted against the corresponding results of the reference laboratory (Spain, $x$-axis) on the logarithmic (base 10) scale. Dotted lines show the equivocal ranges (negative/positive cut-off values), while the solid line represents the quadratic regression model. The only outlier is shown in green.

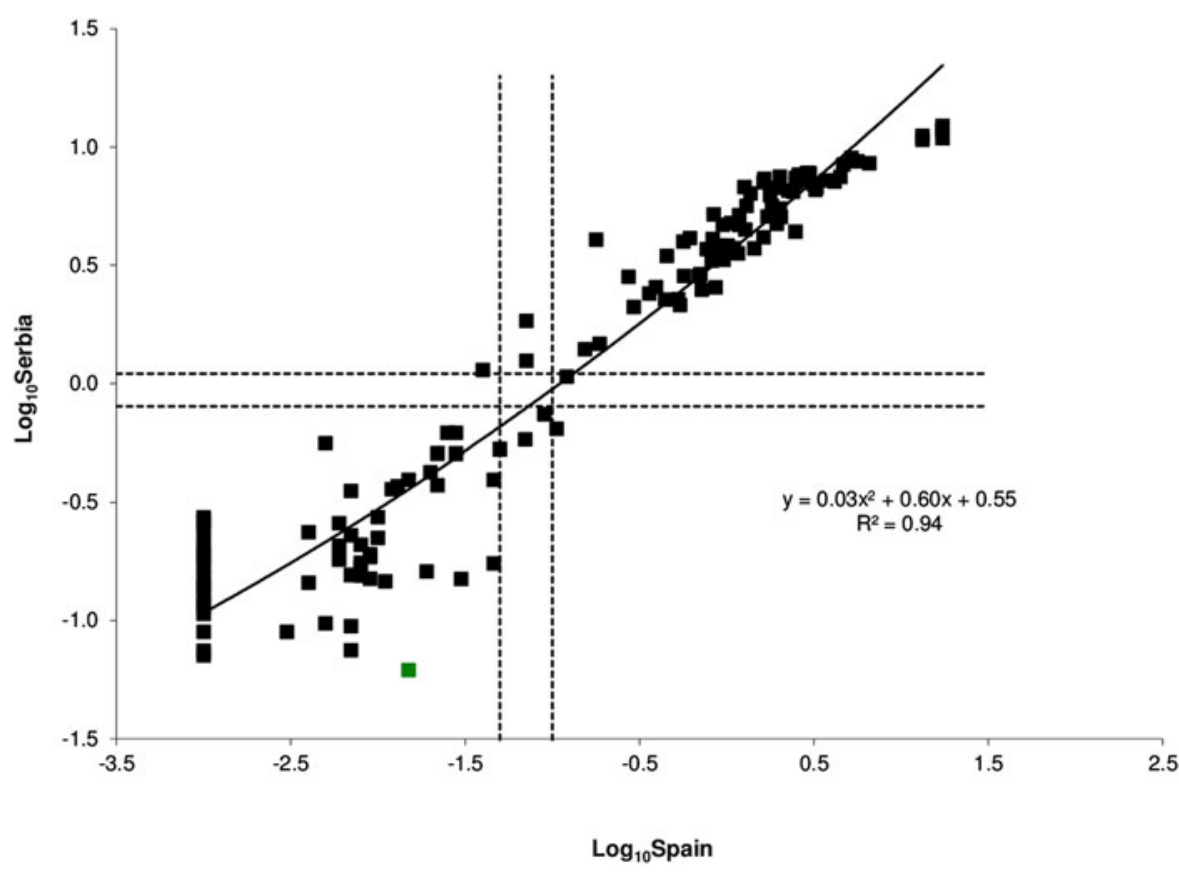

Table 1. Association of VZV seropositivity with demographic features of study subjects in Vojvodina, Serbia, 2015-16

\begin{tabular}{|c|c|c|c|c|}
\hline Characteristic & No. of samples & $\%$ VZV seropositivity & $95 \% \mathrm{Cl}$ & $P$ \\
\hline Gender & & & & 0.58 \\
\hline Male & 1788 & 84.9 & $83.2-86.5$ & \\
\hline Female & 1782 & 84.2 & $82.5-85.9$ & \\
\hline Area of residence & & & & 0.24 \\
\hline Northern Vojvodina & 948 & 85.9 & $80.9-85.5$ & \\
\hline Central Vojvodina & 1511 & 83.5 & $81.6-85.3$ & \\
\hline Southern Vojvodina & 1111 & 84.9 & $82.7-86.9$ & \\
\hline Age group (years) & & & & $<0.001$ \\
\hline$<1$ & 100 & 75.0 & $65.7-82.4$ & \\
\hline $1-4$ & 400 & 41.3 & $36.5-46.1$ & \\
\hline $5-9$ & 513 & 73.7 & $69.7-77.3$ & \\
\hline $10-14$ & 512 & 87.5 & $84.4-90.1$ & \\
\hline $15-19$ & 575 & 92.7 & $90.3-94.6$ & \\
\hline $20-24$ & 200 & 94.0 & $89.8-96.5$ & \\
\hline $25-29$ & 200 & 94.0 & $89.8-96.5$ & \\
\hline $30-34$ & 200 & 96.5 & $93.0-98.3$ & \\
\hline $35-39$ & 200 & 96.0 & $92.3-98.0$ & \\
\hline $40-49$ & 200 & 97.0 & $93.6-98.6$ & \\
\hline $50-59$ & 200 & 99.0 & $96.4-99.7$ & \\
\hline$\geqslant 60$ & 270 & 99.6 & $97.9-99.9$ & \\
\hline Total & 3570 & 84.6 & $83.4-85.8$ & \\
\hline
\end{tabular}

with a VZV seropositive status. The adjusted odds ratios for seropositivity ranged from $3.9(3.0-5.2)$ for children aged 5-9 years to 379.4 (95\% CI $52.7-2730.4)$ for adults aged $\geqslant 60$ years (Table 2).
Figure 3 shows graphically the robust increase in VZV seroprevalence with the age of respondents, particularly during the first years of life to adolescence. VZV seropositivity in infants up to 1 year $(75 \%)$ declined by almost half in the first year 


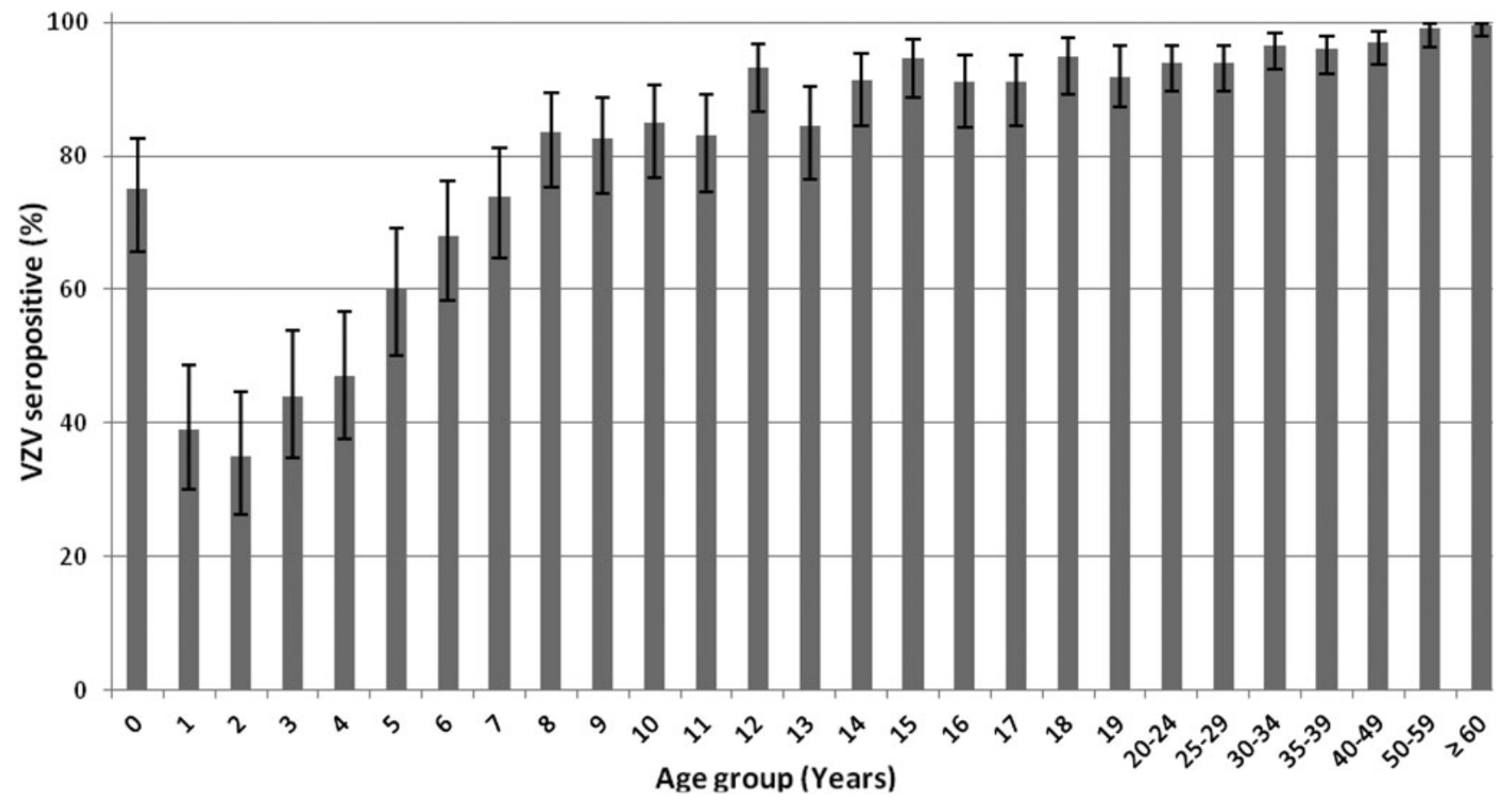

Fig. 3. Age-specific standardised seroprevalence of VZV with $95 \%$ Cls, in Vojvodina, Serbia, 2015-16.

Table 2. Multivariable logistic regression analysis of risk factors for VZV infection

\begin{tabular}{|c|c|c|c|}
\hline Variable & $\begin{array}{l}\text { \% Prevalence } \\
\qquad(95 \% \mathrm{Cl})\end{array}$ & $\begin{array}{l}\text { Adjusted OR } \\
\qquad(95 \% \mathrm{Cl})\end{array}$ & $P$-value \\
\hline Gender & & & 0.52 \\
\hline Female & $84.9(83.2-86.5)$ & Reference & \\
\hline Male & $84.2(82.5-85.9)$ & $1.1(0.9-1.3)$ & \\
\hline Region & & & 0.47 \\
\hline Central & $83.5(81.6-85.3)$ & Reference & \\
\hline South & $84.9(82.7-86.9)$ & $1.1(0.9-1.4)$ & 0.35 \\
\hline North & $85.9(83.6-88.1)$ & $1.2(0.9-1.5)$ & 0.28 \\
\hline Age (years) & & & $<0.0001$ \\
\hline$<1$ & $75.0(65.7-82.4)$ & $4.2(2.6-6.9)$ & $<0.0001$ \\
\hline $1-4$ & $41.3(36.5-46.1)$ & Reference & \\
\hline $5-9$ & $73.7(69.7-77.3)$ & $3.9(3.0-5.2)$ & $<0.0001$ \\
\hline $10-14$ & $87.5(84.4-90.1)$ & $9.9(7.1-13.8)$ & $<0.0001$ \\
\hline $15-19$ & $92.7(90.3-94.6)$ & $17.9(12.4-26.0)$ & $<0.0001$ \\
\hline $20-24$ & $94.0(89.8-96.5)$ & $22.2(12.0-41.1)$ & $<0.0001$ \\
\hline $25-29$ & $94.0(89.8-96.5)$ & $22.3(12.0-41.2)$ & $<0.0001$ \\
\hline $30-34$ & $96.5(93.0-98.3)$ & $39.1(17.9-85.4)$ & $<0.0001$ \\
\hline $35-39$ & $96.0(92.3-98.0)$ & $34.0(16.3-70.9)$ & $<0.0001$ \\
\hline $40-49$ & $97.0(93.6-98.6)$ & $45.8(19.8-105.7)$ & $<0.0001$ \\
\hline $50-59$ & 99.0 (96.4-99.7) & $139.6(34.2-570.2)$ & $<0.0001$ \\
\hline$\geqslant 60$ & 99.6 (97.9-99.9) & $379.4(52.7-2730.4)$ & $<0.0001$ \\
\hline
\end{tabular}

OR, odds ratio.

bald test.
(39\%) and remained at about that same level (35\%) in the second year of life. From this point on, seropositivity began to gradually increase with some fluctuations between the ages of 11/12 and $13 / 14$ years. By the age of $4,47 \%$ of young children already had VZV-specific antibodies, while that percentage increased to $60 \%$ by 5 years. At the age of school entry $(6 / 7$ years in the Serbian educational system), $68 \%$ and $74 \%$ of children, respectively, had acquired VZV-specific immunity. Intensive acquisition of immunity continued during school years, with a gradual increase in seroprevalence. By the end of primary education, $91 \%$ of 14 -year olds were seropositive.

A moderate rise in seropositivity was observed in older school children and teenagers, leaving $7 \%$ seronegative respondents in the 15-19 years age group (Fig. 3, Tables 1 and 3). The proportion of seronegative adults gradually declined from $6 \%$ in the $20-29$ years age group to $4 \%$ in adults aged $35-39$ years and then to $3 \%$ among those aged 40-49 years. A very small proportion (1\%) of adults aged 50 years and older remained susceptible to infection. About $6 \%$ of females of reproductive age (15-39 years old) were seronegative. This percentage was slightly less when the typical range for reproductive age was used (5.5\% for 15-49 years). The proportion of susceptible women was highest $(8 \%)$ in young adulthood (20-24 years), declining to $3 \%$ in those aged 35-39 and 40-49 years (Table 3).

\section{Anti-VZV antibody titres}

Figure 4 displays the anti-VZV titres of respondents, given as geometric mean titres (GMT) expressed in ESEN2-standardised $\mathrm{IU} / \mathrm{ml}$, according to: age (A) and age and gender (B). The overall GMT $(0.54 \mathrm{IU} / \mathrm{ml}$; 95\% CI 0.50-0.59) increased with age in parallel with the increase in seropositivity (Figs 3 and 4, Table 1). Apart from the negative values between 1 and 4 years, three 
Table 3. Proportion of VZV seronegative respondents by age and gender in Vojvodina, Serbia, 2015-16 ${ }^{\text {a }}$

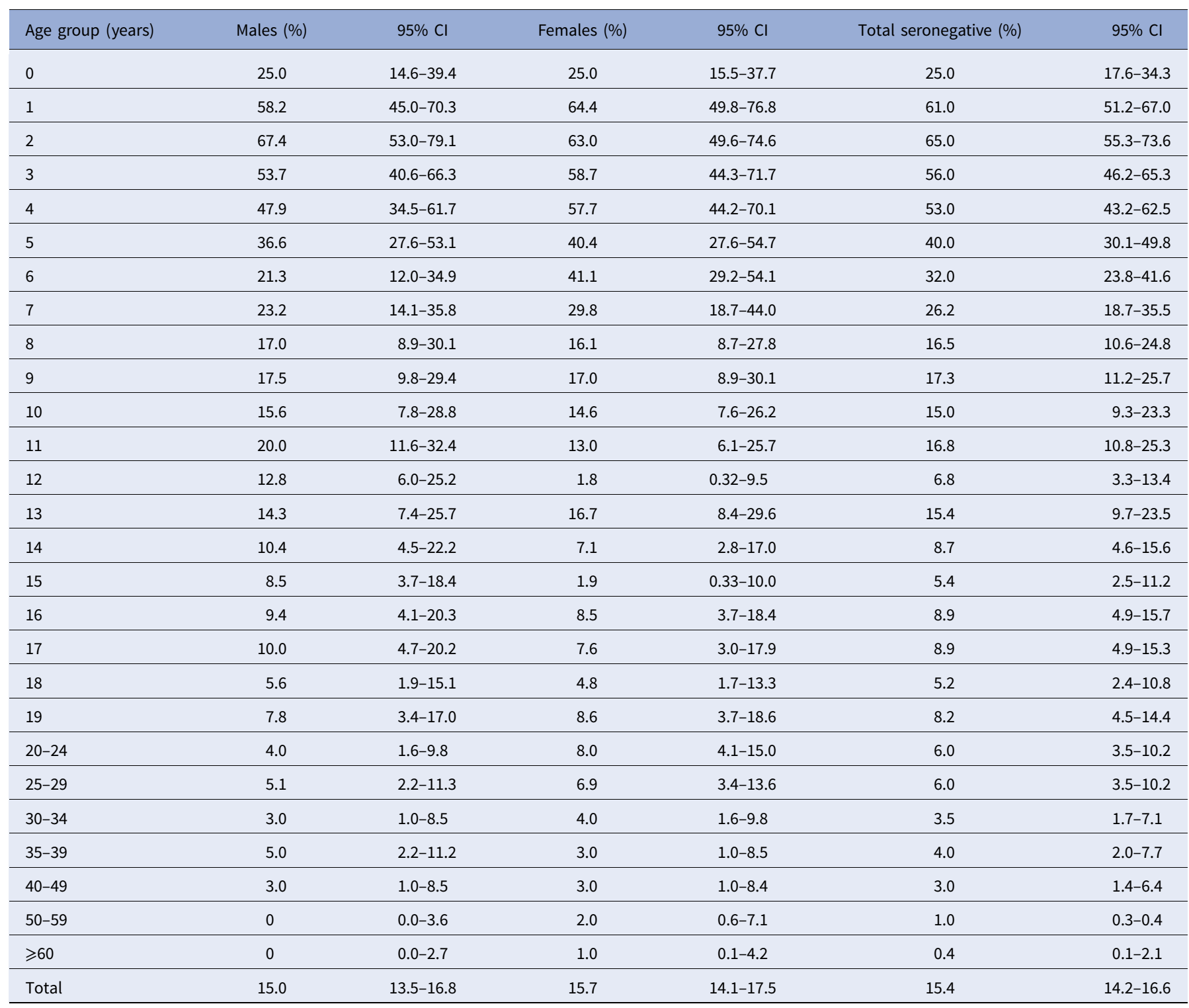

${ }^{\mathrm{a}} P \leqslant 0.01$ for differences in seroprevalence across all age groups, for each gender and in total.

main patterns are distinguishable: (i) an $\sim 8$-fold gradual increase (from 0.07 to $0.55 \mathrm{IU} / \mathrm{ml}$ ) between 4 and 8 years, while seropositivity doubles from $>40$ to $>80 \%$; (ii) a stabilisation period between 9 and 11 years with $\sim 80 \%$ seropositives associated with GMT at $\sim 0.55 \mathrm{IU} / \mathrm{ml}$; and (iii) a period with wider fluctuations at higher GMT $(\sim 0.98 \mathrm{IU} / \mathrm{ml})$ compared with previous years, corresponding to $\sim 90 \%$ seropositives, from age 12 onwards. The maximum GMT among female respondents $(1.4 \mathrm{IU} / \mathrm{ml})$ was detected at the age of 15 years, while the maximum GMT among male respondents $(1.2 \mathrm{IU} / \mathrm{ml})$ was detected in those aged $50-59$ years. GMT did not differ by gender in total $(0.56$; $95 \%$ CI $0.51-0.62$ for males vs. 0.53 ; $95 \%$ CI $0.47-0.58$ for females), or in any age groups.

\section{Discussion}

The high incidence of varicella in Serbia [9] implies correspondingly high levels of collective immunity; however, the VZV- specific seroprofile of the population had never been assessed previously. Few sparse serosurveys conducted in small subgroups at risk of severe clinical forms of the disease [e.g. 15] did not allow the estimation of the overall VZV seroprevalence. This paper is the first to describe the current VZV seroepidemiology in Vojvodina, Serbia. Our study was based on the format of the ESEN2 project that enabled direct inter-laboratory comparisons of serological data $[7,8,13]$. The high natural immunity against varicella (84.6\%) is associated with an almost absolute (98.7\%) seropositivity in adults $\geqslant 40$ years old. The estimated VZV seroprofile for Serbia proved to resemble those of most other European countries in the pre-vaccine era $[4,5,7]$, with acquisition of antibodies primarily in childhood and increasing seroprevalence with age.

The higher seroprevalence detected in newborns and infants $<1$ year of age (75\%) than in the $1-4$ years age group $(41.3 \%)$ is due to the waning of maternal anti-VZV antibodies in the first months of life, as documented previously $[4,5]$. By 5 years of 


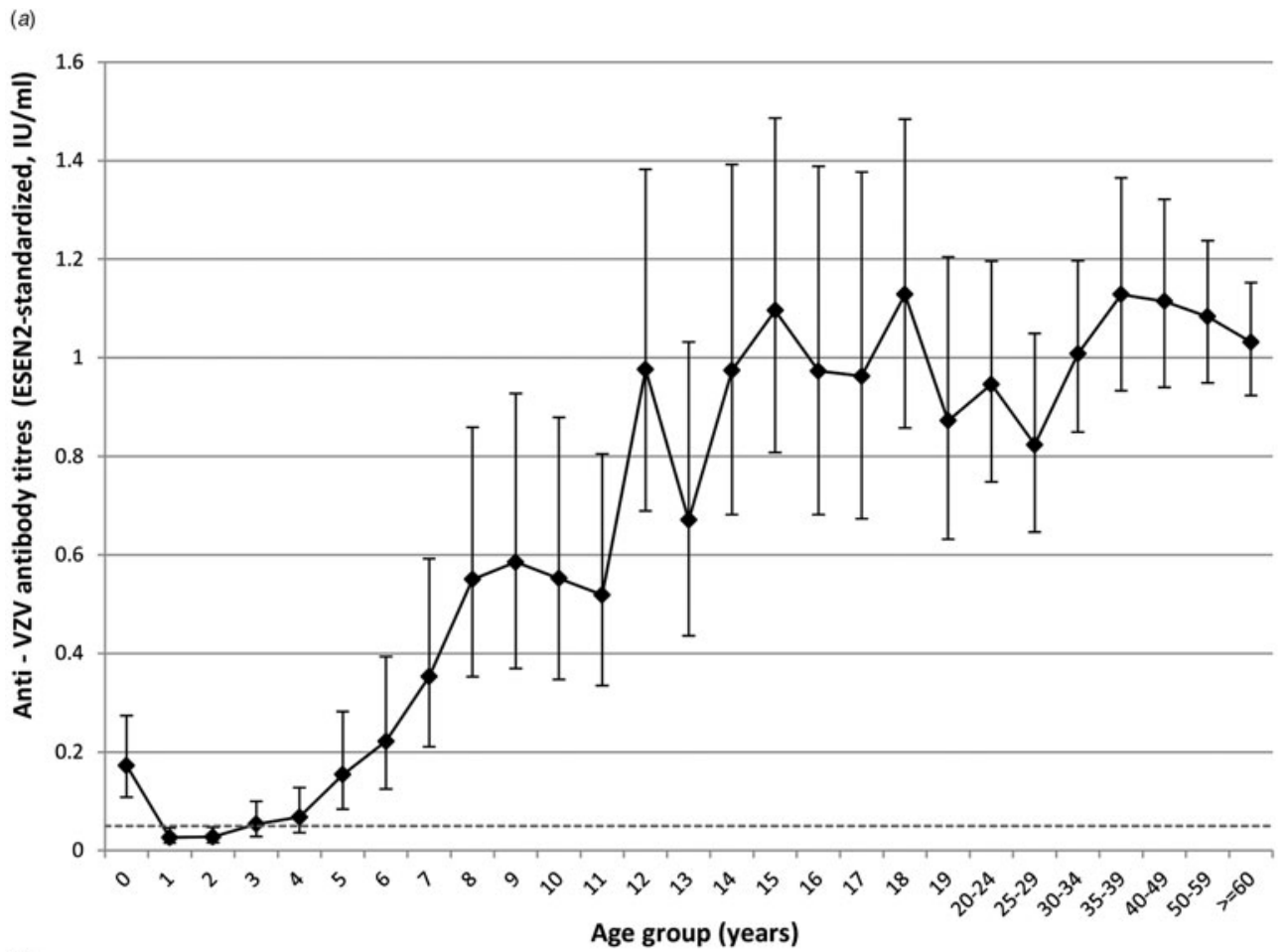

(b)

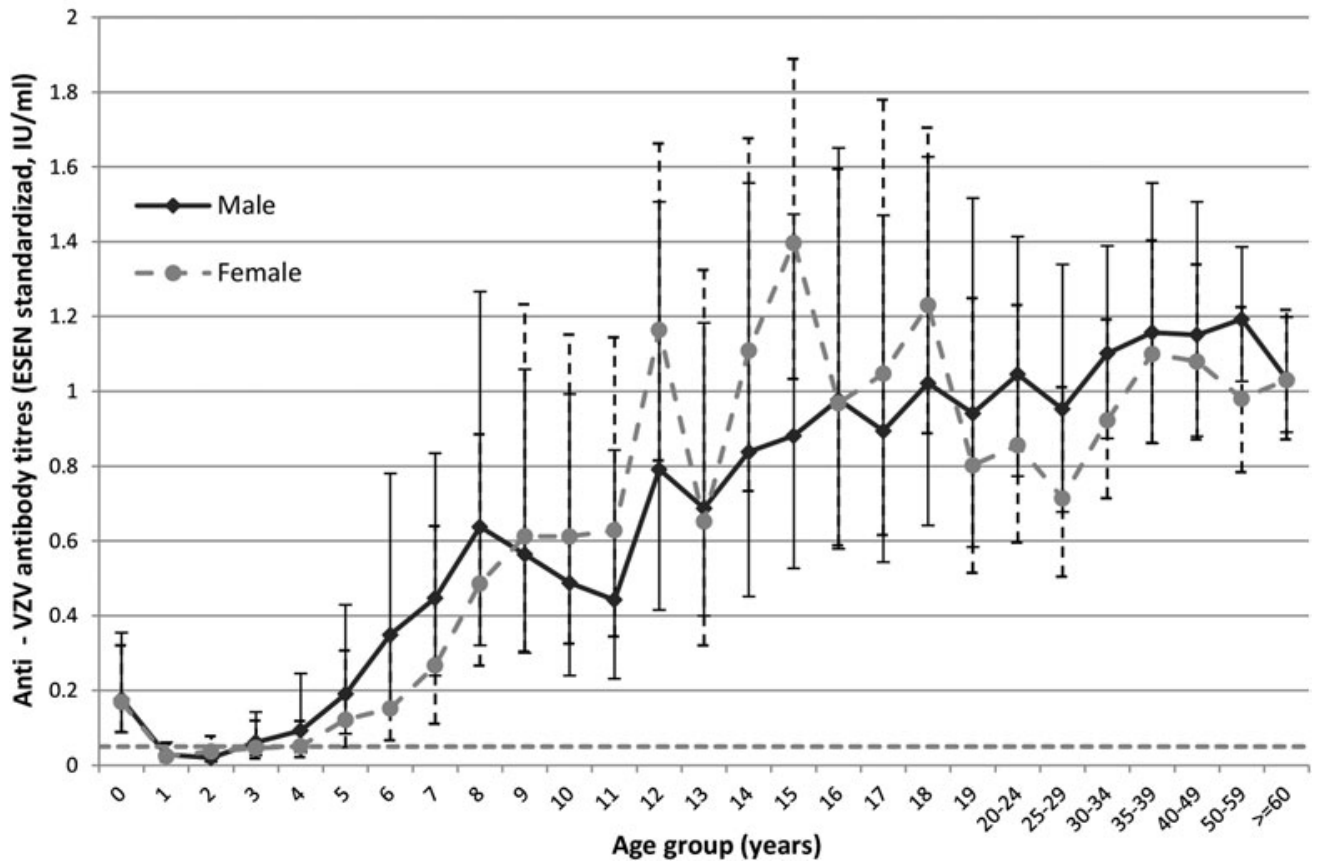

Fig. 4. Anti-VZV antibody titres given as geometric mean titres (GMT) expressed in standardised ESEN2 units IU/ml, according to age (a) and according to age and gender (b), in the 3570 study subjects aged 29 days-83 years from Vojvodina, Serbia; $95 \%$ Cls are also displayed. The dashed lines indicate the cut-off for positive results $(0.05 \mathrm{IU} / \mathrm{ml})$.

age, $60 \%$ of children were already seropositive similarly to the majority of EU/EEA countries in the pre-vaccine era [7]. Recent surveillance data point to an increase in the age-specific incidence of varicella in children aged 1-4 years compared with the 5-9 years age group [16]. This trend, commonly observed in EU/EEA countries, may be explained by the earlier and increased preschool and day care centre usage where the chances of VZV exposure are greater $[7,17,18]$. The $>90 \%$ VZV seroprevalence found in teenagers and adolescents 15-19 years is in line with the rates reported in all other EU/EEA countries except Italy $[4,5]$.

Still, in Serbia, $7 \%$ of adolescents $15-19$ years and $3 \%$ of adults older than 20 years remain susceptible to VZV infection and prone to serious complications of varicella $[4,5]$. The somewhat larger pool of susceptible female respondents of reproductive 
age ( $6 \%$ of women $v s .<5 \%$ of women in most EU countries except Italy and Ireland), in particular, may be a cause for concern. Substantial feto-maternal morbidity is related to VZV infection due to the higher risk of congenital varicella syndrome and neonatal varicella $[2,5]$. The situation is worrying given that in Serbia $\sim 50 \%$ of children are born annually to women aged $20-29$ years; thus, the susceptibility rate in this age group (7.5\%) applied to half of the average birth cohort of 65000 translates to 2400 seronegative pregnant women and an equal number of newborns on an annual basis [19].

A recommendation for VZV serological testing of recently exposed pregnant women for the purpose of passive postexposure immunisation was recently introduced into Serbian legislation [20]. The administration of varicella-zoster immune globulin (VZIG) within $96 \mathrm{~h}$ of VZV exposure is strongly indicated in susceptible pregnant women to prevent severe maternal chickenpox and its complications. Although justified, the administration of VZIG may reduce, but not eliminate, the risk of fetal infection. Therefore, anti-VZV testing of non-pregnant women without history of varicella and immunisation of seronegatives remains the most effective way to prevent varicella in pregnancy, congenital varicella syndrome and neonatal varicella [21].

Variations of GMT for VZV antibodies with age and corresponding seroprevalence together shed light on the dynamics of natural immunity to VZV in the population. The high GMT in older age groups may be a consequence of natural boosting in conditions of incessant VZV circulation in the population [22, 23]. The increase in GMT with advancing age, as observed in other studies too [22-24], supports the established risk between depression of cell-related immunity with ageing and HZ development. Frequent varicella occurrence and recurrent $\mathrm{HZ}$ episodes in patients with impaired cellular immunity underscore the importance of cell-mediated immune response in the host defence against VZV [1, 17].

Similarly to reports from other EU/EEA countries, we found no significant age-specific differences in VZV seroprevalence or GMT by gender [5]. Lower GMT values for women than for men from age 20 years onwards (with the exception of the 4049 age group) were reported in the Netherlands; GMT were still above the cut-off and increased with age [24].

Varicella vaccine (licensed since 2009 in Serbia) is sparsely used ( $<500$ doses yearly); consequently, its impact on VZV collective immunity is negligible. Critical determinants of the seroepidemiology of varicella vary remarkably between temperate and tropical regions pertaining to climate factors, population density, social mixing patterns and urbanisation level [2, 17]. Recent climatic changes due to ozone depletion and global warming, even in temperate regions like Serbia's territory, may have an impact on the age-specific varicella incidence and subsequent susceptibility pattern in older age groups [17]. A connection between area of residence in Vojvodina and VZV seropositivity was not established by this survey. A small number of countries, including Italy, identified regional variations in VZV seroepidemiology, possibly attributable to climate specifics and differences in population density [23].

A major strength of this study is the direct comparability of obtained anti-VZV results to those of other European countries, achieved through the standardisation process. The use of convenience samples of residual sera for the compilation of the serum bank may introduce selection biases [7]. However, a study from Australia yielded comparable estimates of immunity, regardless of the method of sera collection (population-based random sampling or residual sera collection) [25], validating residual sera collection as an appropriate sampling strategy to provide population immunity data. The geographical representativeness of the study sample in relation to the population of Vojvodina, with the pre-defined stratification of the serum bank according to the last census at the municipal level, further reinforces the validity of obtained results.

Despite the potential limitations, our results provide insights into the overall VZV seroprevalence in the Serbian population based on the findings in the province of Vojvodina. The analogous age structure in conjunction with the large size of Vojvodina, which corresponds to more than one-quarter of the population of Serbia, support the induction of conclusions for the whole country. The lack of associations between VZV seropositivity and gender or area of residence reinforces the validity of this inductive syllogism. Besides similar demographic characteristics of Vojvodina and the rest of the country, there are similarities in a number of other factors that can influence VZV transmission dynamics, such as the population density, average household size, the level of child care attendance, infant vaccination coverage and climate. Nevertheless, the possibility that seroprevalence data might differ had the serum bank included samples from all over the country cannot be excluded.

In the ongoing pre-vaccine era, natural infection provides a high level of collective immunity in the population of Vojvodina, with the highest VZV transmission in children of preschool age. This study revealed epidemiologically relevant gaps in VZV immunity among adolescents (7\%), young adults $(6 \%)$ and especially women of childbearing age (6\%). The detected gaps support the adoption of the official recommendations for varicella immunisation of non-immune adolescents and young adults, including non-pregnant women of childbearing age. The current national strategy mandates the immunisation of certain categories of patients at high risk for varicella complications, their family members and health care professionals. Any adjustments to this strategy, whether they include the presumptive immunisation of those with a negative history of varicella or serological testing of those with a negative or uncertain self-reported varicella history and the vaccination of susceptibles, should be based on the risk of VZV exposure and transmission, cost-efficacy studies and assessment of the validity of reported chickenpox history, to determine vaccine eligibility. Such information is currently lacking in Serbia and, therefore, further studies are deemed necessary to underpin a cost-effective varicella immunisation strategy. The seroprevalence data obtained here provide invaluable information on VZV immunity of the population and may be used to inform vaccination policy decisions in Serbia.

Supplementary material. The supplementary material for this article can be found at https://doi.org/10.1017/S0950268818001619

Acknowledgements. The authors would like to thank all health care workers who were involved in the collection of sera samples. The authors also wish to thank Eržebet Ač Nikolić and Zorica Šeguljev for their invaluable advice that helped improve the study design. Our special thanks to the laboratory staff of the Virology Department of IPH Vojvodina for technical assistance. The authors are grateful to Zoran Radovanović for the critical review of the manuscript and useful suggestions.

Financial support. This work was supported by the IPH of Vojvodina. ZL-C was supported by the Serbian Ministry of Education, Science and Technological Development (grant number 174019 for the period 2011-2017).

Conflict of interest. None. 


\section{References}

1. Gershon AA and Gershon MD (2013) Pathogenesis and current approaches to control of varicella-zoster virus infections. Clinical Microbiology Reviews 26, 728-743.

2. World Health Organization (2014) Varicella and herpes zoster vaccines: WHO position paper, June 2014. The Weekly Epidemiological Record 89, 265-288.

3. Bonanni P et al. (2009) Varicella vaccination in Europe - taking the practical approach. BMC Medicine 7, 26.

4. Helmuth IG et al. (2015) Varicella in Europe - a review of the epidemiology and experience with vaccination. Vaccine 33, 2406-2413.

5. European Centre for Disease Prevention and Control (2015) Varicella Vaccination in the European Union. Stockholm: ECDC, Available at http://ecdc.europa.eu/en/publications/Publications/Varicella-Guidance2015.pdf (Accessed 15 December 2016).

6. Carrillo-Santisteve $\mathbf{P}$ and Lopalco PL (2014) Varicella vaccination: a laboured take-off. Clinical Microbiology and Infection 20, 86-91.

7. Nardone A et al. (2007) The comparative sero-epidemiology of VaricellaZoster virus in eleven countries in the European region. Vaccine 25, 78667872 .

8. de Ory F et al. (2006) European seroepidemiology network 2: standardization of assays for seroepidemiology of varicella zoster virus. Journal of Clinical Virology 36, 111-118.

9. Institute of Public Health of Serbia 'Dr Milan Jovanović Batut' (2016). The annual report on infectious diseases in the Republic of Serbia for 2015. [In Serbian]. Available at http://www.batut.org.rs/index.php?category_id=140 (Accessed 29 December 2016).

10. Official Gazette of the Republic of Serbia No. 15/2016 [Law on protection of population from infectious diseases]. [In Serbian]. Available at http://www.paragraf.rs/propisi/zakon_o_zastiti_stanovnistva_od_zaraznih bolesti.html (Accessed 30 December 2016).

11. Official Gazette of the Republic of Serbia No. 88/2017 [Rulebook on immunization and drug prescription]. [In Serbian]. Available at http:// www.paragraf.rs/propisi/pravilnik_o_imunizaciji_i_nacinu_zastite_lekovima. html (Accessed 28 January 2018).

12. Statistical Office of the Republic of Serbia (2011) Census of population, households and dwellings in the Republic of Serbia. [In Serbian/English]. Available at http://pod2.stat.gov.rs/ObjavljenePublikacije/Popis2011/ Nacionalna\%20pripadnost-Ethnicity.pdf (Accessed 11 December 2015).
13. Kafatos G, Andrews N and Nardone A (2005) ESEN2 project. Model selection methodology for inter-laboratory standardization of antibody titres. Vaccine 23, 5022-5027.

14. Statistica 13 (StatSoft Inc., Tulsa, OK, USA). Available at www.statsoft. com.

15. Kuljić-Kapulica N et al. (1989) Detection of antibodies to cytomegaloviruses, herpes simplex viruses and varicella-zoster viruses in persons positive for human immunodeficiency virus antibodies. [In Serbian]. Srpski Arhiv Za Celokupno Lekarstvo (Serbian Archives of Medicine) 117, 483-489.

16. Institute of Public Health of of Vojvodina. Communicable diseases in Vojvodina for 2015. Annual report. 2016. [In Serbian]. Available at http://www.izjzv.org.rs/publikacije/ZarazneBolesti/ZB_2015.pdf (Accessed 2 December 2016).

17. Papaloukas O, Giannouli G and Papaevangelou V (2014) Successes and challenges in varicella vaccine. Therapeutic Advances in Vaccines 2, 39-55.

18. Sočan $\mathbf{M}$, Berginc $\mathbf{N}$ and Lajović J (2010) Varicella susceptibility and transmission dynamics in Slovenia. BMC Public Health 10, 360.

19. Institute of Public Health of Serbia 'Dr Milan Jovanović Batut' (2016) Health statistical yearbook of Republic of Serbia for 2015. [In Serbian/ English]. Available at http://www.batut.org.rs/download/publikacije/pub2015. pdf (Accessed 23 January 2017).

20. Official Gazette of the Republic of Serbia No. 3/2017 [Rulebook on mandatory health checks of certain categories of employees in facilities under sanitary supervision, mandatory and recommended medical examination]. [In Serbian]. Available at http://www.pravno-informacioni-sistem. rs/SlGlasnikPortal/reg/viewAct/4a670b6d-72c7-45f1-a639-1aec0a0516bc (Accessed 15 May 2017).

21. Marin M et al. (2007) Advisory Committee on Immunization Practices, Centers for Disease Control and Prevention (CDC) prevention of varicella: recommendations of the Advisory Committee on Immunization Practices (ACIP). Morbidity and Mortality Weekly Report 56, 1-40.

22. Gabutti G et al. (2001) Serological study group. The seroepidemiology of varicella in Italy. Epidemiology and Infection 126, 433-440.

23. Gabutti G et al. (2008) Seroepidemiology group. The epidemiology of varicella zoster virus infection in Italy. BMC Public Health 8, 372.

24. van Lier A et al. (2013) Varicella zoster virus infection occurs at a relatively young age in The Netherlands. Vaccine 31, 5127-5133.

25. Kelly H et al. (2002) A random cluster survey and a convenience sample give comparable estimates of immunity to vaccine preventable diseases in children of school age in Victoria, Australia. Vaccine 20, 3130-3136. 